\title{
Radiographic characteristics in congenital scoliosis associated with split cord malformation: a retrospective study of 266 surgical cases
}

Fan Feng ${ }^{1}$, Haining $\operatorname{Tan}^{1}$, Xingye $\mathrm{Li}^{1}$, Chong Chen ${ }^{1}$, Zheng $\mathrm{Li}^{1}$, Jianguo Zhang ${ }^{1}$ and Jianxiong Shen ${ }^{1,2^{*}}$

\begin{abstract}
Background: Vertebrae, ribs, and spinal cord are anatomically adjacent structures, and their close relationships are clinically important for planning better corrective surgical approach. The objective is to identify the radiographic characteristics in surgical patients with congenital scoliosis (CS) and coexisting split cord malformation (SCM).

Methods: A total of 266 patients with CS and SCM underwent surgical treatment at our hospital between May 2000 and December 2015 was retrospectively identified. The demographic distribution and radiographic data were collected to investigate the characteristics of spine curve, vertebral, rib, and intraspinal anomalies. According to Pang's classification, all patients were divided into two groups: type I group is defined as two hemicords, each within a separate dural tube separated by a bony or cartilaginous medial spur, while type II group is defined as two hemicords within a single dural tube separated by a nonrigid fibrous septum.
\end{abstract}

Results: There were 104 patients (39.1\%) in Type I group and 162 patients (60.9\%) in Type II group. SCM was most commonly found in the lower thoracic and lumbar regions. The mean length of the septum in Type I SCM was significantly shorter than Type II SCM (2.7 vs. 5.2 segments). Patients in Type I group had a higher proportion of kyphotic deformity (22.1\%). The vertebral deformities were simple in only $16.5 \%$ and multiple in $83.5 \%$ of 266 cases. Patients in Type I group presented higher prevalence of multiple (90.4\%) and extensive (5.1 segments) malformation of vertebrae. In addition, hypertrophic lamina and bulbous spinous processes were more frequent in Type I group (29.7\%), even developing into the "volcano-shape" deformities. Rib anomalies occurred in 62.8\% of all patients and $46.1 \%$ of them were complex anomalies. The overall prevalence of other intraspinal anomalies was 42. 9\%. The most common coexisting intraspinal anomalies was syringomyelia (30.5\%).

Conclusion: The current study, with the largest cohort to date, demonstrated that patients with CS and coexisting SCM presented high prevalence of multiple vertebral deformities, rib and intraspinal anomalies. The length of the split segment in Type I SCM was shorter than that in Type II SCM. Compared with Type II SCM, patients with Type I SCM presented with higher incidence of kyphotic deformity, more extensive and complicated vertebral anomalies, and more complex rib anomalies.

Keywords: Congenital scoliosis, Split cord malformation, Intraspinal anomalies, Deformity

\footnotetext{
* Correspondence: shenjianxiong@medmail.com.cn

${ }^{1}$ Department of Orthopedics, Peking Union Medical College Hospital,

Chinese Academy of Medical Science, Peking Union Medical College, Beijing,

China

2Department of Orthopedic Surgery, Peking Union Medical College Hospital,

Chinese Academy of Medical Science, Peking Union Medical College, No. 1

Shuai Fu Yuan, Wang Fu Jing Street, Beijing 100730, China
}

(c) The Author(s). 2017 Open Access This article is distributed under the terms of the Creative Commons Attribution 4.0 International License (http://creativecommons.org/licenses/by/4.0/), which permits unrestricted use, distribution, and reproduction in any medium, provided you give appropriate credit to the original author(s) and the source, provide a link to the Creative Commons license, and indicate if changes were made. The Creative Commons Public Domain Dedication waiver (http://creativecommons.org/publicdomain/zero/1.0/) applies to the data made available in this article, unless otherwise stated. 


\section{Background}

Congenial scoliosis (CS) is a kind of rare spinal deformity. Large population studies utilizing screening low-dose radiography of the spine suggested a congenital scoliosis prevalence of $0.5 \%$ to $0.11 \%$ [1, 2]. CS identified at birth that is a byproduct of anomalous vertebral development in the embryo (the first 8 weeks of gestation) [3]. During this period, the bony elements of the spine are forming, and the neuraxis is completing its infolding, closing the neural tube [4]. These events are closely related, and any intrauterine event that causes CS could also be associated with an occult intraspinal anomalies (incidence ranged from $18 \%$ to $38 \%$ ) [5-7]. These anomalies include syringomyelia, tethering of the cord, low conus, lipoma, but the most common one is split cord malformation (SCM) $[3,7,8]$.

SCM is a relatively rare form of a congenital neural anomaly and tethered spinal cord syndrome. According to Pang's classification $[9,10]$, type I SCM is defined as two hemicords, each within a separate dural tube separated by a bony or cartilaginous medial spur, while type II SCM is defined as two hemicords within a single dural tube separated by a nonrigid fibrous septum. Both these conditions may limit movement of the spinal cord within the canal, possibly placing the patient at an increased neurological risk when performing surgical treatment for congenital scoliosis [11-14].

Previous studies had revealed the close relationships between rib anomalies and vertebral or intraspinal anomalies [15-17]. Vertebrae, ribs, and spinal cord are anatomically adjacent structures, and a local developmental deficiency in this area may explain the synchronous occurrence of these anomalies [18]. These various anomalies are substantial clues for better identifying of the scoliotic characteristics, and at the same time clinically important for planning better corrective surgical approach.

However, to the best of our knowledge, there have been no studies that have specifically investigated the radiographic details of CS patients associated with SCM. Therefore, the purpose of this study is to identify the vertebral, rib and intraspinal anomalies in surgical patients with congenital scoliosis and coexisting split cord malformation. Based upon these findings, it could potentially be useful for improving surgical strategies in these individuals.

\section{Methods}

After obtaining approval from the institutional review board in our hospital, 281 consecutive patients of congenital scoliosis associated with SCM undergoing spinal correction surgery between May 2000 and December 2015 were retrospectively reviewed. Among these patients, 266 fulfilled the following inclusion criteria: (1) definite diagnosis of congenital scoliosis with SCM; (2) patients with complete medical records and radiological data. 21 Patients with previous spinal surgery, spinal fractures were excluded. Each patient received examinations of an entire spine magnetic resonance imaging (MRI) and computerized tomography (CT) to evaluate the type and location of SCM. According to Pang's classification for SCM $[9,10]$, all patients were divided into Type I group and Type II group.

\section{Radiographical measurements}

The standing posterior-anterior radiographs were reviewed to identify the type of the curvature according to the classification proposed by the Scoliosis Research Society [19]: thoracic (apex between T2 and T11), thoracolumbar (apex between T12 and L1), lumbar (apex between L2 and L4). The patients with kyphotic deformities on the standing lateral radiographs were also recorded. Congenital kyphosis is defined as a sagittal plane deformity: thoracic region (T5-T12) $>40^{\circ}$ or thoracolumbar region (T10-L2) $>30^{\circ}$ or kyphosis at lumbar region (L1-L5) or angular kyphosis at any segments of spine [20].

The plain radiograph and 3-dimensional reconstruction CT of the entire spine were reviewed to evaluate the presence of vertebral deformities as well as rib anomalies. The vertebral anomalies and the type of spine deformity were categorized according to the classification proposed by Winter et al. [21, 22] and McMaster et al. [23] into failures of vertebral segmentation, failures of vertebral formation, and mixed anomalies. Furthermore, vertebral anomalies were classified as single malformations (failure of formation of one vertebra or failure of segmentation of the adjacent two vertebrae) or multiple malformations (failure of segmentation of more than two vertebrae, or mixed anomalies of multiple vertebras). Their number and site of the vertebral deformities were also recorded.

Rib anomalies which included number changes (increased or decreased ribs) and structural deformities (fused, bifid, and widened/irregular ribs), can be classified as simple or complex type [15]. Patients with simple type of rib anomaly were defined as a localized fusion of two or three ribs or a small chest wall defect resulting from an anomalies of one or two ribs or an absence of a rib. Patients with complex type of rib anomalies were described as multiple extensive rib fusions, usually without a fixed pattern, association with a large chest wall defect due to an absence or variation of ribs. The side and location of rib anomalies were recorded as well, including upper thoracic (T1-T4), middle thoracic (T5$\mathrm{T} 8$ ), or lower thoracic (T9-T12).

\section{Data collection}

All of the measurements were performed by an independent observer. Each parameter was measured for 2 
times, and the average values were calculated in both groups.

\section{Statistics}

The data were analyzed using SPSS version 17.0 for Windows (SPSS Inc., Chicago, IL).The independent sample $t$ test and Pearson Chi-square test was performed to analyze the differences between the 2 groups where appropriate. Statistical significance was considered with a $P$ value $<0.05$.

\section{Results}

The Type I group consisted of 76 female and 28 males (38.2\%) with an average age of 14.0 years (range, 4$39 \mathrm{yr}$ ); while the Type II group consisted of 114 female and 48 males $(61.8 \%)$ with a mean age of 14.3 years (range, 3-38 yr). No significant differences were detected between two groups in gender $(P=0.633)$ or age $(P=0.715)$. Most of the split were located at the lower thoracic and lumbar regions. Location details are shown in Fig. 1. The length of the split segment was measured according to the number of vertebral bodies it spanned. In Type I group, the length of the split segment extended with an average of 2.7 (range, 1-8) segments. While in Type II group, it varied between 1and 16 segments, with a mean of 5.2 segments. This difference was statistically significant $(P<0.001)$ (Table 1$)$.

The average Cobb angle of the main curve was $71.5^{\circ}$ (range $14^{\circ}-165^{\circ}$ ) in Type I group and $68.9^{\circ}$ (range $30^{\circ}-$ $\left.158^{\circ}\right)$ in Type II group. There were no significant differences between two groups $(P=0.434)$. Thoracic curve was the most common curve pattern $(179,67.3 \%)$, followed by thoracolumbar $(59,22.2 \%)$ and lumbar $(28$, $10.5 \%)$. Though the most common location of the septum located at thoracolumbar region, while the apex of major curve mostly located at the middle thoracic and thoracolumbar regions (Fig. 2). Moreover, kyphotic deformity was found to be more frequent in Type I group $(25,24.0 \%)$ than in Type II group (22, 13.6\%) $\left(\chi^{2}=4.762, P=0.029\right)$ (Table 1$)$.

\section{Vertebral anomalies}

A total of 44 cases (16.5\%) presented with single malformation of vertebral anomalies, whereas the other 222 cases $(83.5 \%)$ had multiple malformations. Failure in segmentation, formation, and mixed anomalies was observed in $28.6 \%, 16.9 \%$, and $54.5 \%$ of cases, respectively. Compared with Type II group, the patients of Type I group presented higher prevalence of multiple malformations and mixed anomalies. Besides, the involved levels of vertebral deformities was also longer (5.1 vs. $3.9, P<0.001)$. The vertebral anomalies in Type I group were most frequently found in both thoracic and lumbar regions, whereas the vertebral anomalies in Type II group were most frequently found only in thoracic region $(P=0.004)$.

Of note, hypertrophic lamina and bulbous spinous processes were present in $32(30.8 \%)$ patients with Type I SCM. Occasionally, three or more adjacent lamina were fused into a massive gnarl, which we described as the "volcano-shape" deformity (Fig. 3) [10]. In contrast, the exuberant neural arches were observed in only 21 cases (13.0\%) of Type II group. There were significant differences between two groups $\left(x^{2}=12.587, P<0.001\right)$ (Table 2).

\section{Rib anomalies}

Rib anomalies occurred in $62.8 \%(167 / 266)$ of the patients. Of these, 90 (53.9\%) had simple anomalies and 77 (46.1\%) had complex anomalies. Compared with

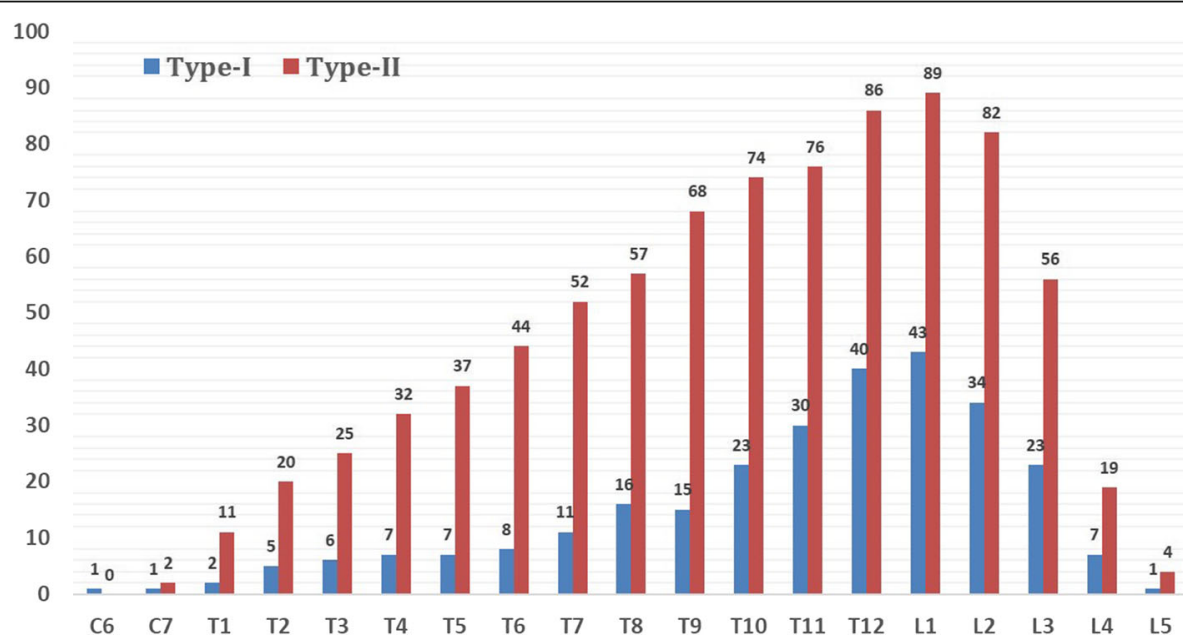

Fig. 1 The location details of septum in two types of split cord malformation 
Table 1 Radiographic characteristics of patients with congenital scoliosis and SCM

\begin{tabular}{lllc}
\hline characteristics & Type I & Type II & P \\
\hline Number of patient, $\mathrm{n}(\%)$ & $104(39.1)$ & $162(60.9)$ & \\
Age (yrs) & $14.0 \pm 6.0$ & $14.3 \pm 5.9$ & 0.715 \\
Sex (M/F) & $28 / 76$ & $48 / 114$ & 0.633 \\
Length of split segment, $\mathrm{n}$ & $2.7 \pm 1.5$ & $5.2 \pm 3.3$ & $<0.001^{*}$ \\
Main curve Cobb angle ( $\left.{ }^{\circ}\right)$ & $71.5 \pm 27.4$ & $68.9 \pm 24.1$ & 0.434 \\
Type of curve, $\mathrm{n}(\%)$ & & & 0.448 \\
$\quad$ Thoracic & $67(64.4)$ & $112(69.1)$ & \\
$\quad$ Thoracolumbar & $23(22.1)$ & $36(22.2)$ & \\
$\quad$ Lumbar & $14(13.5)$ & $14(8.6)$ & \\
Kyphotic deformity & & & 0.029 * \\
$\quad$ With, $\mathrm{n}(\%)$ & $25(24.0)$ & $22(13.6)$ & \\
$\quad$ Without & 79 & 140 & \\
\hline
\end{tabular}

SCM split cord malformation; * means statistical difference

Type II group, the patients of Type I group presented higher prevalence of complex rib anomalies $(29.7 \%$ vs. $47.0 \%, P=0.028)$. Rib anomalies occurred mostly on the concavity of the scoliosis in $65.9 \%$ of cases (110/ 167), followed by bilateral (22.8\%) and the convexity (11.4\%). There were no significant differences in the type and distribution of rib anomalies between two groups (Table 3). With regard to the rib structural changes, the most common was fused ribs (50.3\%), followed by bifid rib combined with fused ribs (21.0\%) and bifid ribs (12.7\%).

\section{Other intraspinal abnormalities}

In this study, a total of $114(42.9 \%)$ patients were found to have other intraspinal anomalies. The most common anomaly was syringomyelia $(81,30.5 \%)$, followed by low conus $(67,25.2 \%)$ and tethered cord $(60,22.6 \%) .29$ patients $(10.9 \%, 15$ with Type I SCM and 14 with Type II SCM) had concurrent anomalies of SCM, syringomyelia, and tethered cord. No significant differences were observed in the distribution between two groups. (Table 4).

\section{Discussion}

The present study is the first investigation with large cohort in the literature that examines vertebral, rib, and intraspinal anomalies at the same time in patients with CS and coexisting SCM. In our study of 266 CS patients, patients with fibrous septum were nearly 1.5 times those with bony septum, which was higher than the results of previous studies $[10,24]$. Regardless of the type, the lower thoracic and lumbar regions were the most common site for SCM. No differences were detected in the distribution between two types of SCM. This conformity could be explained by Pang's theory for the formation of $\mathrm{SCM}$, a common origin of both malformation that an adhesion between the ectoderm and endoderm - the accessory neurenteric canal-leads to an endomesenchymal tract which bisects the spinal cord [9]. Pang et al. [10] also showed that he split lengths of the 19 Type I lesions (2.97 levels) were longer than that of 18 Type II lesions (1.17 levels). However, in our series, the length of the split segment in both group were both longer and the septum in Type I group was significantly shorter than that in Type II group (2.7 vs. 5.2). Therefore, there are still reasons to concern about the neurological risk due to the tethering function of the septum, anchoring the spinal hemicords.

Ghandhari et al. [17] reported 202 CS patients, in which vertebral defects were failure in formation (53.5\%), failure in segmentation (31.7\%), and a mixed form of both (14.9\%). Their rates are in conformity with previous reports for common CS patients [16, 25].

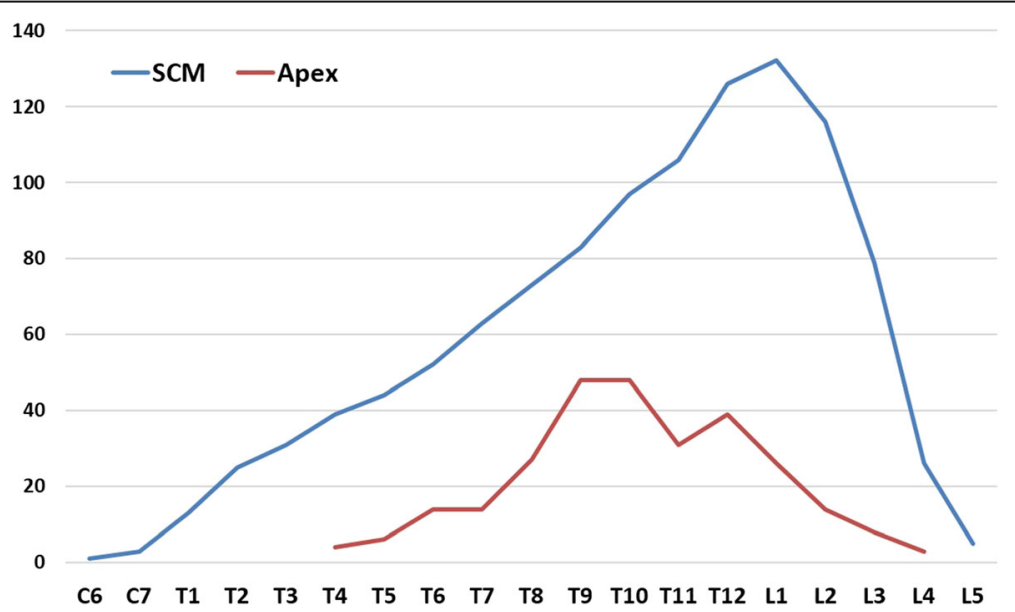

Fig. 2 The location distribution of the septum (one peak) and the apex of scoliosis (two peaks) 


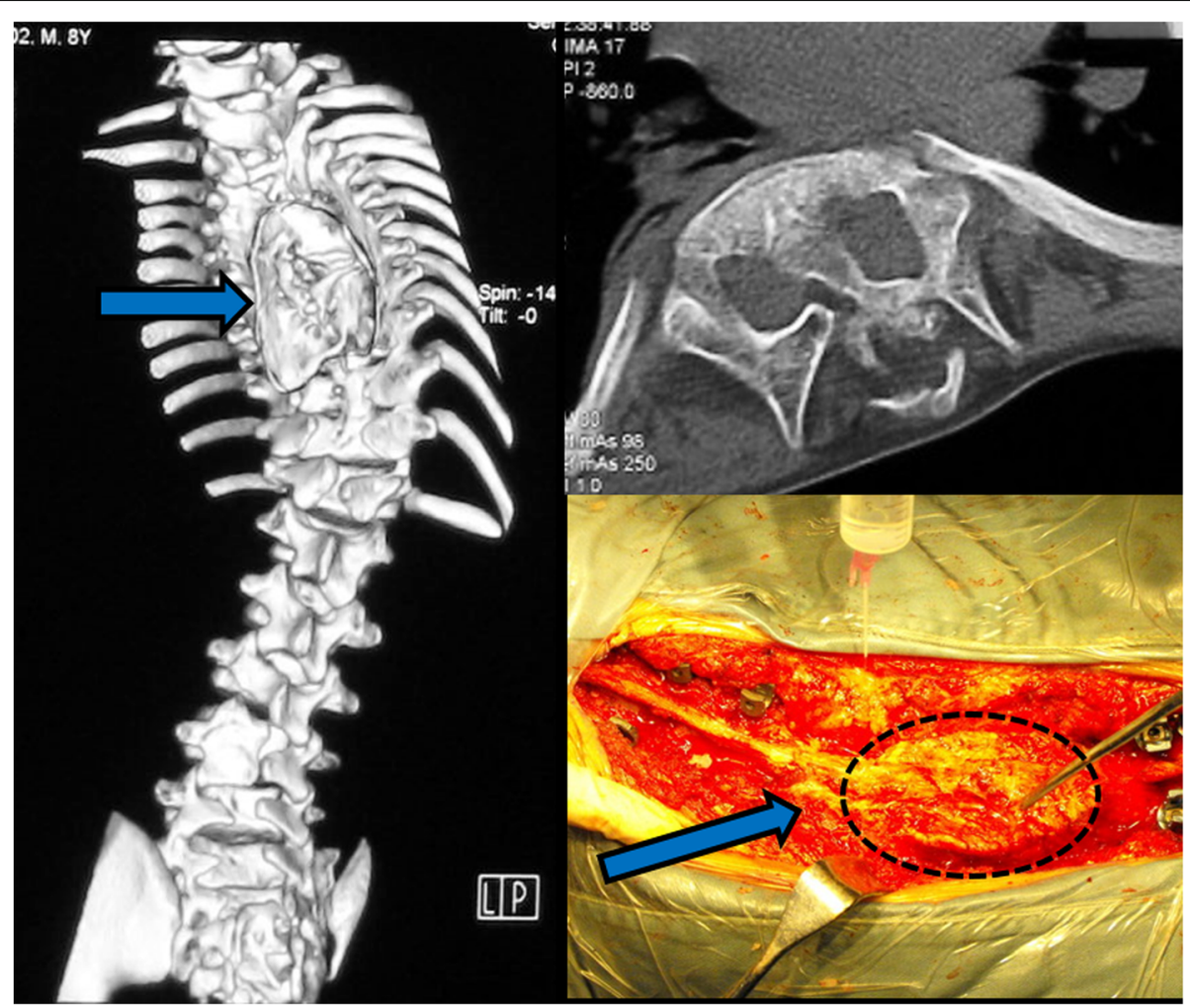

Fig. 3 Images of an eight-year-old male patient diagnosed with congenital scoliosis and the type I split cord malformation. Three-dimension CT showed hypertrophic lamina and bulbous spinous processes in the middle thoracic region. These exuberant neural arches can be described as the "volcano-shape" deformity (with arrows in the figure)

Table 2 Vertebral anomalies in patients with congenital scoliosis and SCM

\begin{tabular}{|c|c|c|c|}
\hline characteristics & Type I $(n=104)$ & Type II $(n=162)$ & $P$ \\
\hline Vertebral deformities, n (\%) & & & $0.001^{*}$ \\
\hline Failure of segmentation & $21(20.2)$ & $55(34.0)$ & \\
\hline Failure of formation & $11(10.6)$ & $34(21.0)$ & \\
\hline Mixed type & $72(69.2)$ & $73(45.1)$ & \\
\hline Malformation, n (\%) & & & $0.015^{*}$ \\
\hline Single malformation & $10(9.6)$ & $34(21.0)$ & \\
\hline Multiple malformation & $94(90.4)$ & $128(79.0)$ & \\
\hline Levels of vertebral deformities, $n$ & $5.1 \pm 2.5$ & $3.9 \pm 2.2$ & $<0.001^{*}$ \\
\hline Location of deformities, n (\%) & & & $0.004^{*}$ \\
\hline T & $65(62.5)$ & $126(77.8)$ & \\
\hline L & $4(3.8)$ & $10(6.2)$ & \\
\hline$T+L$ & $35(33.7)$ & $26(16.0)$ & \\
\hline Exuberant neural arches, $\mathrm{n}(\%)$ & & & $<0.001^{*}$ \\
\hline with & $32(30.8)$ & $21(13.0)$ & \\
\hline without & $72(69.2)$ & $141(87.0)$ & \\
\hline
\end{tabular}


Table 3 Rib anomalies in patients with congenital scoliosis and SCM

\begin{tabular}{|c|c|c|c|}
\hline characteristics & Type I $(n=104)$ & Type II $(n=162)$ & $P$ \\
\hline Rib anomalies, n (\%) & & & 0.854 \\
\hline without & $38(36.5)$ & $61(37.7)$ & \\
\hline with & $66(63.5)$ & $101(62.3)$ & \\
\hline Type, n (\%) & & & $0.023^{*}$ \\
\hline simple & $35(53.0)$ & $71(70.3)$ & \\
\hline complex & $31(47.0)$ & $30(29.7)$ & \\
\hline Side of scoliosis, n (\%) & & & 0.216 \\
\hline concave & $46(69.7)$ & $64(63.3)$ & \\
\hline convex & $4(6.1)$ & $15(14.9)$ & \\
\hline bilateral & $16(24.2)$ & $22(21.8)$ & \\
\hline $\begin{array}{l}\text { Type of structural } \\
\text { changes, } \mathrm{n}(\%)\end{array}$ & & & 0.540 \\
\hline fused ribs & $32(48.5)$ & $52(51.5)$ & \\
\hline bifid ribs & $5(7.6)$ & $15(14.9)$ & \\
\hline $\begin{array}{l}\text { bifid rib combined } \\
\text { with fused ribs }\end{array}$ & $13(19.7)$ & $22(21.8)$ & \\
\hline
\end{tabular}

SCM split cord malformation; * means statistical difference

However, in our series, failure in segmentation, formation, and mixed type was observed in $28.6 \%, 16.9 \%$, and $54.5 \%$ of 266 cases. The prevalence of mixed type was much higher than those reported in common CS patients. In fact, this result is in line with previous studies that intraspinal anomaly were more common in patients with congenital scoliosis resulting from mixed defects $[3,8]$. Therefore, single malformation composed of only $16.5 \%$ of vertebral deformities, while $83.5 \%$ of cases had multiple malformations. Furthermore, when compared with Type II group, the patients in Type I group presented higher prevalence of multiple malformations and mixed anomalies of vertebral deformities. And the length of involved levels is also larger. These findings may have some important implications for the pedicle screw-based correction of CS with SCM. Firstly, the vertebral deformities of Type I SCM patients tend to more complex. These severe and irregular deformities

Table 4 Other intraspinal abnormalities in patients with congenital scoliosis and SCM

\begin{tabular}{llll}
\hline characteristics & $\begin{array}{l}\text { Type I } \\
(\mathrm{n}=104)\end{array}$ & $\begin{array}{l}\text { Type II } \\
(\mathrm{n}=162)\end{array}$ & $\mathrm{P}$ \\
\hline $\begin{array}{l}\text { With other intraspinal } \\
\text { abnormalities, } \mathrm{n}(\%)\end{array}$ & $46(44.2)$ & $68(42.0)$ & 0.717 \\
$\quad$ Syringomyelia & $32(30.8)$ & $49(30.2)$ & 0.928 \\
Tethered cord & $27(26.0)$ & $33(20.4)$ & 0.287 \\
$\quad$ Low conus & $30(28.8)$ & $37(22.8)$ & 0.271 \\
$\quad$ Intraspinal masses & $3(2.9)$ & $4(2.5)$ & 0.836 \\
\hline SCM split cord malformation & & &
\end{tabular}

make the spinal anatomic landmark obscure, which may increase the possibility of malpositioned pedicle screws. Secondly, multiple malformations and mixed anomalies of vertebral deformities, as well as the length of involved levels, would severely decrease the flexibility of spine. In contrast, the Type II SCM always associated with simple vertebral abnormality, thus it is more likely to get better curve correction. Consequently, it is not hard to understand the results of previous studies $[12,13]$ that the correction rate of Type II is higher than that of Type I SCM. The spine surgeon should have a clear that the most important issue for these patients is to arrest the progression of scoliosis and deterioration of neurological deficits, rather than just pursuing overcorrection of spinal deformity.

Notably, hypertrophic lamina and bulbous spinous processes, even developing into the "volcano-shape" deformity (Fig. 3), were present in $32(30.8 \%)$ patients with Type I SCM. In contrast, these exuberant neural arches were seen in only $13.0 \%$ Type II cases. In Pang's series [10], similar findings were found in 16 of 19 Type I cases and 2 of the 18 Type II cases. Traditionally, to avoid creating a neural deficit or aggravating a preexisting neural deficit, resection of the septum has been indicated for patients with SCM prior to any procedure for correcting the spinal deformity [10, 24, 26-28]. However, in case with "volcano-shape" deformity, it is technically difficult to remove the posterior elements at the level of septum during the prophylactic neurosurgery.

Xue et al. [16] reported that rib anomalies were present in $50.3 \%$ of Chinese patients with CS. Similarly, the prevalence of rib anomalies was $57.4 \%$ in another report by Ghandhari et al. [17]. However, in this study, we found a considerably higher prevalence (62.8\%) of rib anomalies among CS patients with SCM. This difference is easy to understand because prior studies have suggested a correlation between rib anomalies and occult intraspinal anomaly (SCM is the most common intraspinal anomaly) [15-17]. The prevalence of intraspinal anomaly was significant higher in the patients with rib anomalies than those without rib anomalies. Thus, as expected, a greater number of rib anomalies can be identified in CS patients with SCM. Furthermore, rib anomalies in the present study consisted of simple anomalies (53.9\%) and complex anomalies (46.1\%). In contrast with previous reports $[15,17](21.0 \sim 29.1 \%)$, the rate of complex rib anomalies was relatively higher, especially in Type I SCM patients. Clinically, these rib anomalies could significantly compromise the correction rate in congenital scoliosis [29].

In a Chinese series [8], the prevalence of syringomyelia, low conus and tethered cord in CS patients were only $18.1 \%, 5.8 \%$ and $11.5 \%$, respectively. Ghandhari et al. [17] reported the intraspinal anomalies were found in 
$21.8 \%$ of patients, including syringomyelia (9.9\%), tethered cord (3\%), low conus (3\%), and intraspinal tumors (2\%). In contrast, we firstly revealed the high prevalence (42.9\%) of intraspinal anomalies in the largest sample of CS patients with SCM. Syringomyelia was detected most frequently (30.5\%), followed by low conus $(25.2 \%)$ and tethered cord (22.6\%). These findings of multiple intraspinal anomalies may be explained by the important embryological mechanisms: the codetermination in the embryonic developmental time of intraspinal anomalies and congenital spinal deformity $[3,30]$. On the other hand, all patients in the current study underwent a full spine MRI. Some earlier studies of the instance of intraspinal anomalies have not demanded this, and as a result, the instance of syringomyelia may be understated, as the syringomyelia has been missed. More importantly, spine surgeons should have a clear knowledge that patients having CS and SCM may also closely associated with other intraspinal anomalies. These coexisting tethering lesions, especially the tethered cord, is stretch-induced functional disorder of the spinal cord and anchors the caudal end of the spinal cord which prevents cephalad movement of the lumbosacral cord [31]. In our experience, it should be prudent to perform prophylactic neurosurgery of spur excision and cord untethering before corrective surgery. Some prior studies had revealed that excision of the spur did not result in a dramatic improvement in the neurological status [24, 32, 33]. For these patients, their neurological deficits may result from other intraspinal anomalies, rather than the only tethering dysfunction of SCM itself.

Two limitations to this study should be addressed. First, this is a retrospective study based on operated cases to demonstrate the radiological features of patients with CS and SCM, which might be helpful to planning better treatment. However, it should be acknowledged that in patients not being operated, the prevalence or extent of anomalies might be different. Second, more basic researches focusing on the pathogenesis of CS and coexisting SCM are warranted to reveal the mechanism of these finding in current study.

\section{Conclusions}

The results of our study, for the first time with the largest sample size, demonstrated the radiographic characteristics of CS patients with coexisting SCM. Patients with coexisting CS and SCM present relatively high incidence of multiple vertebral deformities, rib and intraspinal anomalies. The length of the split segment in Type I SCM was significantly shorter than that in Type II SCM. Compared with Type II SCM, patients with Type I SCM presented with higher incidence of kyphotic deformity, more extensive and complicated vertebral anomalies, and more complex rib anomalies. These findings may provide important clues for better understanding their clinical features and thus improving the safety and efficacy of surgical treatment for patients with congenital scoliosis and coexisting split cord malformation.

\section{Abbreviations \\ CS: congenital scoliosis; SCM: split cord malformation}

\section{Acknowledgements}

Not applicable.

\section{Funding}

This work was supported by National Natural Science Foundation of China (Grant Number: 81,330,044).

\section{Availability of data and materials}

The data will not be shared, because the data are patient data and were collected on the agreement that the individual-level data will not be publicly distributed and only aggregated data must be publicized.

\section{Authors' contributions}

FF, HT, and JS contributed to the conception and design of the study. FF, JZ, CC, ZL and XL contributed to the analysis, and all authors contributed to the interpretation of the results. FF drafted the article; all authors revised it critically and approved the final version submitted for publication. All authors read and approved the final manuscript.

\section{Ethics approval and consent to participate}

This study was approved by the Institutional Review Board of Peking Union Medical College Hospital. Because of the anonymous nature of the data, the requirement for informed consent was waived.

Consent for publication

Not applicable.

\section{Competing interests}

The authors declare that they have no competing interests.

\section{Publisher's Note}

Springer Nature remains neutral with regard to jurisdictional claims in published maps and institutional affiliations.

Received: 2 December 2016 Accepted: 12 October 2017

Published online: 23 October 2017

\section{References}

1. Shands AR Jr, Eisberg HB. The incidence of scoliosis in the state of Delaware; a study of 50,000 minifilms of the chest made during a survey for tuberculosis. J Bone Joint Surg Am. 1955;37-a(6):1243-9.

2. Dickson RA, Stamper P, Sharp AM, Harker P. School screening for scoliosis: cohort study of clinical course. Br Med J. 1980;281(6235):265-7.

3. Basu PS, Elsebaie $H$, Noordeen MH. Congenital spinal deformity: a comprehensive assessment at presentation. Spine. 2002;27(20):2255-9.

4. Tsou PM, Yau A, Hodgson AR. Embryogenesis and prenatal development of congenital vertebral anomalies and their classification. Clin Orthop Relat Res. 1980:152:211-31.

5. Bradford DS, Heithoff KB, Cohen M. Intraspinal abnormalities and congenital spine deformities: a radiographic and MRI study. J Pediatr Orthop. 1991:11(1):36-41.

6. Liu YT, Guo LL, Tian Z, Zhu WL, Yu B, Zhang SY, Qiu GX. A retrospective study of congenital scoliosis and associated cardiac and intraspinal abnormities in a Chinese population. Eur Spine J. 2011;20(12):2111-4.

7. McMaster MJ. Occult intraspinal anomalies and congenital scoliosis. The Journal of bone and joint surgery American. 1984;66(4):588-601. 
8. Shen J, Wang Z, Liu J, Xue X, Qiu G. Abnormalities associated with congenital scoliosis: a retrospective study of 226 Chinese surgical cases. Spine. 2013;38(10):814-8.

9. Pang D, Dias MS, Ahab-Barmada M. Split cord malformation: part l: a unified theory of embryogenesis for double spinal cord malformations. Neurosurgery. 1992;31(3):451-80.

10. Pang D. Split cord malformation: part II: clinical syndrome. Neurosurgery. 1992;31(3):481-500.

11. Ayvaz M, Alanay A, Yazici M, Acaroglu E, Akalan N, Aksoy C. Safety and efficacy of posterior instrumentation for patients with congenital scoliosis and spinal dysraphism. J Pediatr Orthop. 2007;27(4):380-6.

12. Ayvaz M, Akalan N, Yazici M, Alanay A, Acaroglu RE. Is it necessary to operate all split cord malformations before corrective surgery for patients with congenital spinal deformities? Spine. 2009;34(22):2413-8.

13. Hui H, Tao HR, Jiang XF, Fan HB, Yan M, Luo ZJ. Safety and efficacy of 1stage surgical treatment of congenital spinal deformity associated with split spinal cord malformation. Spine. 2012;37(25):2104-13.

14. Shen J, Zhang J, Feng F, Wang Y, Qiu G, Li Z. Corrective surgery for congenital scoliosis associated with split cord malformation: it may be safe to leave Diastematomyelia untreated in patients with intact or stable neurological status. The Journal of bone and joint surgery American. 2016; 98(11):926-36.

15. Tsirikos Al, McMaster MJ. Congenital anomalies of the ribs and chest wall associated with congenital deformities of the spine. The Journal of bone and joint surgery American. 2005;87(11):2523-36.

16. Xue X, Shen J, Zhang J, Zhao H, Li S, Zhao Y, Liang J, Qiu G, Weng X. Rib deformities in congenital scoliosis. Spine. 2013;38(26):E1656-61.

17. Ghandhari H, Tari HV, Ameri E, Safari MB, Fouladi DF. Vertebral, rib, and intraspinal anomalies in congenital scoliosis: a study on 202 Caucasians. Eur Spine J. 2015;24(7):1510-21.

18. Wattanasirichaigoon D, Prasad C, Schneider G, Evans JA, Korf BR. Rib defects in patterns of multiple malformations: a retrospective review and phenotypic analysis of 47 cases. Am J Med Genet A. 2003;122A(1):63-9.

19. Scoliosis Research Society Terminology Committee. A glossary of scoliosis terms. Spine. 1976;1:57-8.

20. Marks DS, Qaimkhani SA. The natural history of congenital scoliosis and kyphosis. Spine. 2009;34(17):1751-5.

21. Winter RB, Moe JH, Eilers VE. Congenital scoliosis. A study of 234 patients treated and untreated. Part l: natural history. The Journal of bone and joint surgery American. 1968;50:1-15.

22. Winter RB, Moe JH, Wang JF. Congenital kyphosis. Its natural history and treatment as observed in a study of one hundred and thirty patients. The Journal of bone and joint surgery American. 1973;55(2):223-56.

23. McMaster MJ, Ohtsuka K. The natural history of congenital scoliosis. A study of two hundred and fifty-one patients. The Journal of bone and joint surgery American. 1982;64(8):1128-47.

24. Mahapatra AK, Gupta DK. Split cord malformations: a clinical study of 254 patients and a proposal for a new clinical-imaging classification. J Neurosurg. 2005;103(6 Suppl):531-6.

25. Suh SW, Sarwark JF, Vora A, Huang BK. Evaluating congenital spine deformities for intraspinal anomalies with magnetic resonance imaging. J Pediatr Orthop. 2001;21(4):525-31.

26. Linder M, Rosenstein J, Sklar FH. Functional improvement after spinal surgery for the dysraphic malformations. Neurosurgery. 1982;11(5):622-4.

27. Goldberg C, Fenelon G, Blake NS, Dowling F, Regan BF. Diastematomyelia: a critical review of the natural history and treatment. Spine. 1984;9(4):367-72.

28. Frerebeau P, Dimeglio A, Gras M, Harbi H. Diastematomyelia: report of 21 cases surgically treated by a neurosurgical and orthopedic team. Childs Brain. 1983:10(5):328-39.

29. Ameri E, Fouladi DF, Ghandhari H, Vahid Tari H, Safari MB. The effect of concomitant rib deformity in congenital scoliosis on spinal curve correction after segmental pedicle screw instrumentation. J Spinal Disord Tech. 2015;

30. Prahinski JR, Polly DW Jr, McHale KA, Ellenbogen RG. Occult intraspinal anomalies in congenital scoliosis. J Pediatr Orthop. 2000;20(1):59-63.

31. Drake JM. Surgical management of the tethered spinal cord-walking the fine line. Neurosurg Focus. 2007;23(2):E4.

32. Miller A, Guille JT, Bowen JR. Evaluation and treatment of diastematomyelia. The Journal of bone and joint surgery American. 1993;75(9):1308-17.

33. Sinha $S$, Agarwal D, Mahapatra AK. Split cord malformations: an experience of 203 cases. Childs Nerv Syst. 2006;22(1):3-7.

\section{Submit your next manuscript to BioMed Central and we will help you at every step:}

- We accept pre-submission inquiries

- Our selector tool helps you to find the most relevant journal

- We provide round the clock customer support

- Convenient online submission

- Thorough peer review

- Inclusion in PubMed and all major indexing services

- Maximum visibility for your research

Submit your manuscript at www.biomedcentral.com/submit
Biomed Central 